\title{
Evaluation of Indian Rural Health Care Centre Programs: By the Application of Data Envelopment Analysis Technique
}

\author{
G.M. Satyanarayana, C.T. Jayadeva and H.V. Ramakrishna
}

\begin{abstract}
India's achievements in the field of rural health care delivery have been less than satisfactory and that burden of diseases among the rural Indian population remains high. Recognizing the importance of rural health in the process of economic and social development and necessary architectural correction in the rural health care delivery system to improve the quality of life of the citizens, the government of India has resolved to launch the National Rural Health Mission (NRHM). Indian rural health policies and programs do not address significantly to improve the health status to the desired level due to lack of efficient evaluation system. This study uses Data Envelopment Analysis (DEA) to evaluate relative efficiency of rural health care programs. A typical statistical approach is characterized has a central tendency approach and it evaluates producers relative to an average producer. DEA is commonly used to evaluate the efficiency of a number of producers. In contrast, DEA compares each producer with only the "best" producers. The technique optimizes the relative efficiency ratio of current inputs over current outputs for each decision-making unit (DMU). The multiple inputs and outputs of heterogeneous rural health programs would be assessed simultaneously and helps to identify whether the programs are performing efficiently or inefficiently when compared to the other existing programs. In this paper, we have focused on the evaluation of programs with particular reference to Chikmagalur District, Karnataka, India.
\end{abstract}

Keywords--- Data Envelopment Analysis, DecisionMaking Unit, National Rural Health Mission

\section{INTRODUCTION}

$\mathrm{T}$ HE recognition that rural health care is a very important part of national health care delivery system, the country has created huge rural health

G.M. Satyanarayana, Research Scholar, Department of Mechanical Engineering, AIT, Karnataka,India.E-mail: satyaait@gmail.com

C.T. Jayadeva, Professor, Department of Mechanical Engineering, Adichunchanagiri Institute of Technology, Chikmagalur, India. E-mail: ctjayadeva@yahoo.co.in

H.V. Ramakrishna, Professor, Department of Mechanical Engineering, Malnad College of Engineering, Hassan, Karnataka, India.E-mail: hvr_2003@yahoo.com infrastructure, along with the formation of a massive health care manpower consisting of over 5 lakhs trained doctors working under plural systems of medicine and a vast frontline of over seven lakhs nurses and other health care workers; 25,000 primary and community health care centers; and 1.6 lakhs sub-centre's [1]. This infrastructure remains underequipped, under-manned and under-financed to cope with the challenge of eradicating major threats to human life. The inadequacy of the current rural health care system is starkly illustrated by the fact that only 35 per cent of the population has access to essential drugs, infant immunization against measles and DPT for children under 12 years is only 60 per cent. Rural India is suffering from long standing health care problem, current rural health policies and programs do not address significantly to improve the health status to the desired level $[1,2]$. In this context it is necessary to evaluate the Indian Rural Health Care programs by the use of mathematical programming technique. Under constrained resources, an overall evaluation measure of efficiency is especially useful for program management and policymaking.

\section{A. Introduction to DEA}

DEA is commonly used to evaluate the efficiency of number of producers. A typical statistical approach is characterized has a central tendency approach and it evaluates producers relative to an average producer. In contrast, DEA compares each producer with only the best producers. By the way, in the DEA literature, a producer is usually referred to as a decision making unit or DMU. In DEA, there are number of producers. The production process for each producer is to take a set of inputs and produce a set of outputs. Each producer has a varying level of inputs and gives a varying level of outputs [3].

A fundamental assumptions behind this method is that if a producer $\mathrm{A}$ is capable of producing $\mathrm{Y}(\mathrm{A})$ units of output with $\mathrm{X}(\mathrm{A})$ inputs, then other producers should also be able to do the same if they were to operate efficiently. Similarly, if producer $\mathrm{B}$ is capable of producing $\mathrm{Y}$ (B) units of output with $\mathrm{X}$ (B) inputs, then other producers should also be capable of the same production schedule. Producers A, B, and others can then be combined to form a composite producer with composite inputs and composite outputs. Since this composite producer does not necessarily exist, it is typically called a virtual producer [3].

The heart of the analysis lies in finding the "best" virtual producer for each real producer. If the virtual producer is better than the original producer by either making more output with the same input or making the same output with less input then 
the original producer is inefficient. The subtleties of DEA are introduced in the various ways that producers A and B can be scaled up or down and combined. Charnes, Cooper, and Rhodes introduced DEA to estimate efficiency of DMUs [3, 4]. It is a nonparametric approach which determines a piecewise linear efficiency frontier along the most efficient companies to derive relative efficiency measures of all other companies. DEA is used by many people in different sectors since the methods are applied and interpreted very easily. DEA identifies an efficient frontier made up of the best practice firms and uses this curve to measure the relative efficiency scores of the least efficient firms. As an advantage, it does not require specification of a production or cost function. It allows us to calculate the technical efficiencies which could be decomposed into scale, congestion, and pure technical efficiencies. For evaluating the relative efficiency of not-for-profit entities this has been advanced as an appropriate and easy method, because it is able to handle multiple inputs and outputs simultaneously. DEA is a unique method to generate relative-efficiency information not usually available from other methods, including the relative efficiency ratio and the amount and source of relative inefficiency in decision units $[3,5,6]$. However, it is not so familiar to health services researchers. These DEA literature, emphasize the strengths of DEA in evaluating efficiency within relatively homogeneous groups of decision units. The objective of our study is to examine whether DEA yields useful information when applied to extremely heterogeneous health activities, namely rural health care programs. Data Envelopment Analysis (DEA) uses nonparametric deterministic mathematical programming to optimize the relative efficiency ratio in each decisionmaking unit (DMU) such as organization, program, service, that utilizes similar inputs to produce similar outputs when compared to a peer group of DMUs. The mathematical model and theoretical base model of DEA have been mentioned in many articles [3,7-10].The efficiency of any DMU is obtained by using a nonlinear programming model, as the maximum of a ratio of weighted outputs to weighted inputs subject to the condition that the ratio for every DMU be less than or equal to unity. Those programs with a positive efficiency ratio of less than 1 are defined as "inefficient" compared to programs with an efficiency ratio of 1 . Those health programs with an efficiency ratio of 1 , while not necessarily efficient in the absolute sense, represent the "best-practice" units when compared with other programs in their subset [4]. A rural health program that is found to be relatively efficient, for instance, may still be able to innovate and improve its operating efficiency. In other words, a rural health program that is found to be inefficient will have inefficiencies at least as large as the amount determined by DEA. Hence, DEA methodology is considered conservative in measuring efficiency $[4,6$, $11]$.

The reason for using the term "Data Envelopment" is this technique uses the current values of chosen multiple inputs and outputs simultaneously in each DMU to generate efficiency boundaries and then compares the relative relationships between other DMUs. It produces a summary scalar efficiency ratio for each DMU in the study and also identifies the amount of inefficiency for each resource in each inefficient DMU. One advantage of the DEA model is that each input and each output variable can be measured independently in any useful unit, without being transformed into a single metric, provided the same variables are utilized for every DMU. Moreover, by not requiring a predetermined specific input-output relationship, the DEA model can use as inputs any factors that significantly affect the output variables. This avoids the problems associated with techniques used to convert and unify variables. The efficiency criterion employed is the maximization of relative efficiency for each program rather than an arbitrary cutoff point; hence, each multiplier (weight) is generated, not a priori, but from actual data for each DMU [4, 11-14].

\section{FRAMEWORK OF THE STUDY}

The data's were collected from NRHM centre, District health office Chikmagalur District, Karnataka, India. Questionnaire techniques was use to gather detailed information about Rural Health centre programs such as provider a characteristics, scope of services, provider stability and productivity, revenues and costs and administrative and financial polices. The database includes 93 randomly selected programs of NRHM (2008-2010).

\section{A. Output and Input Variables}

Only two main categories are considered in a DEA model: input and output. This study model has controllable and uncontrollable variables. Input controllable and uncontrollable variables $\left(\mathrm{v}_{1}, \mathrm{v}_{2}--\mathrm{v}_{\mathrm{n}}\right)$. Output controllable and uncontrollable variables $\left(\mathrm{u}_{1}, \mathrm{u}_{2}--\mathrm{u}_{\mathrm{n}}\right)$. Health programs that produce more outputs with given inputs are considered to be relatively more efficient. For our study, outputs can be any product of the rural health program, such as services provided and patients served. As mentioned previously, inputs can be any factors that affect significantly the production of outputs. According to previous studies potential input and output variables were identified and justified. To select no redundant output variables, correlation analysis was used. From these output variables as dependent variables, input variables were selected from the results of correlation and stepwise regressions. Then controllable (discretionary) and uncontrollable (nondiscretionary) inputs and outputs were considered by classifying the selected inputs and outputs according to their relationship to managerial decisions.

The rural primary health care programs are heterogeneity in nature; it was evident not only in their outputs but also in their inputs. Most of the variables used in this study had coefficients of variation (s.d./mean) greater than 100 percent. Accordingly, all of the uncontrollable input variables were classified into two or three (0-1) categories in order to limit the range of peer programs that belonged to the same comparative group. The common major services in rural primary health care programs are medical services. Since no direct measure of quality of medical services was available in the data set, the provision of 
medical services was considered by type of provider, instead of an aggregated measure for all medical services. For this study, we used three main types of health care providers: doctors, ANMs, Health assistants. In addition to the three medical output measures, "total encounters," the summation of medical other encounters was considered as an "uncontrollable" output in the DEA model. This methodology took total volume of the program into account in the efficiency comparisons and allowed consideration in the model of other non medical services that the center produced.

The input factors used in the model were: Doctors (DOCs), ANMs, health workers male, Health workers female, Nurse-Midwife, Health assistants, Administrative staffs, Lab assistants, service area population size, age of program, percentage of users under 4 years old. The service area population size and the percentage of users under 4 years old were used as control variables of users health need (or demand).The program performance is depends on the age of program, because the younger programs may have managerial strategies different from those of well-organized programs.

\section{THE DEA MODEL}

From 93 programs of National Rural Health Mission (NRHM) programs in the data set, only 53 have complete data (including 0 ) for each chosen variable; further, only 27 of them provided services by Doctors (DOCs), ANMs (Auxiliary Nurse Midwife), Health Workers male, Health Workers female, Nurse-Midwife, Health Assistants, Lab Assistants, service area population size, age of program, percentage of users under 4 years old. Due to technical difficulties in the LPP software, those programs that contained zero values in controllable input and output variables were not used. Therefore, only 27 programs were used to test the applicability of DEA. DEA is mathematical models that measure the relative efficiency of decision-making units with multiple inputs and outputs but with no obvious production function to aggregate the data in its entirety. Relative efficiency is defined as the ratio of total weighted output to total weighted input. The empirical model for a rural health care center $\mathrm{k}$ (DMUk) can be presented as follows:

The Objective is to:

$$
\begin{array}{clc}
\multirow{2}{*}{\text { OUTPUTS }} & \text { Controllable } & \begin{array}{c}
\mathrm{u}_{1} \text { DOC's Encounters } \\
\mathrm{u}_{2} \text { Health Asst. Encounters } \\
\mathrm{u}_{3} \text { ANM's Encounters }
\end{array} \\
& & \\
\text { Uncontrollable } & +\mathrm{u}_{4} \text { Total Encounters }
\end{array}
$$

$\operatorname{Max} h_{K}$

$$
\begin{array}{ll} 
& \mathrm{v}_{1} \text { DOC's } \\
& \mathrm{v}_{2} \text { ANM's } \\
\text { Controllable } & \mathrm{v}_{3} \text { Health workers Male } \\
& \mathrm{v}_{4} \text { Health workers Female } \\
& \mathrm{v}_{5} \text { Nurse }- \text { Midwife } \\
& \mathrm{v}_{6} \text { Administrative staff s } \\
& \\
& \mathrm{v}_{7} \text { Population size } \\
\text { Uncontrollable } & \mathrm{v}_{8} \text { Age of Program } \\
& \mathrm{v}_{9} \text { Users Age }
\end{array}
$$

Subject to

$$
\begin{gathered}
\mathrm{h}_{\mathrm{j}} \leq 1, \mathrm{j}=1,2, \ldots 27, \\
0<\in \leq \mathrm{u}_{1} \ldots \ldots \mathrm{u}_{4} \text { and } \\
0<\in \leq \mathrm{v}_{1} \ldots \ldots \mathrm{v}_{9}
\end{gathered}
$$

where

$\mathrm{hj}=$ the efficiency ratio for any $\mathrm{DMUj}$;

$\mathrm{j}=1,2, \ldots, 27$;

u's and v's = artificial weights generated from the model;

$\epsilon=$ a non-Archimedean infinitesimal.

\section{THE PROGRAM EFFICIENCY RELATIONSHIP}

To summarize the program efficiency relationship, the data base had been classified into three categories according their operational characteristics of the rural health care center programs such as sub centers (SCs), primary health centers (PHCs), community health centers (CHCs).

\section{A. Efficiency Relationships between Rural Health Care \\ Centre's (SCs, PHCs and CHCs)}

The operational characteristics the rural health care center programs in the data base had been classified into three categories: sub centers (SCs), primary health centers (PHCs), community health centers (CHCs). Table 1 shows that the Sub Centers and PHCs have a higher proportion of efficient programs, the CHCs have a higher proportion of inefficient programs.

Table 1: Relation between Program Efficiency and Rural Health Care Centers

\begin{tabular}{|l|c|c|c|}
\hline \multirow{2}{*}{$\begin{array}{c}\text { Health care } \\
\text { centers }\end{array}$} & \multicolumn{2}{|c|}{ Number/Percent of Programs } & \multirow{2}{*}{ Total } \\
\cline { 2 - 3 } & $\begin{array}{c}\text { Efficient } \\
\text { Programs }\end{array}$ & $\begin{array}{c}\text { Inefficient } \\
\text { Programs }\end{array}$ & \\
\hline \multirow{2}{*}{$\begin{array}{l}\text { Sub } \\
\text { Centers }\end{array}$} & 06 & 03 & 0 \\
\cline { 2 - 3 } & 66.66 & 33.33 & \\
\hline CHCs & 3 & 4 & \multirow{2}{*}{07} \\
\cline { 2 - 3 } & 42.87 & 57.13 & \\
\cline { 2 - 3 } PHCs & 07 & 04 & \multirow{2}{*}{11} \\
\hline \multirow{2}{*}{ Total } & 63.63 & 36.36 & \multirow{2}{*}{27} \\
\cline { 2 - 3 } & 16 & 11 & \\
\hline
\end{tabular}

\section{B. Efficiency Relationships between Rural Health Care} Centre's and Population Size

Service area population size is related to the forms of Rural Health Care Centers. Most CHCs were located in comparatively populous service areas, and most PHCs in communities with smaller populations. With the exception of two PHCs, all programs serving small populations were efficient, if not self-evaluators, regardless of their Health Centers. In medium and large population, the proportions of efficient and inefficient programs areas were similar. Table 2 shows the distribution of efficient programs as related to population size and Health Centers. The only one inefficient program in small population areas were $\mathrm{PHC}$ and the only PHC in a large population area was also inefficient. While the only inefficient Sub Centers was located in a large service area, one inefficient program in large service areas were CHC. 
Table 2: Distribution of Efficient Programs as Related to Population Size and Health Care Centers

\begin{tabular}{|l|c|c|c|c|}
\hline \multirow{2}{*}{$\begin{array}{c}\text { Population } \\
\text { Size }\end{array}$} & \multicolumn{4}{|c|}{$\begin{array}{c}\text { Health care centers program } \\
\text { (number efficient programs/number } \\
\text { programs) }\end{array}$} \\
\cline { 2 - 5 } & SC & CHC & PHC & Total \\
\hline Small & $2 / 2$ & $2 / 2$ & $5 / 7$ & $9 / 11$ \\
\hline Medium & $2 / 2$ & $1 / 2$ & $2 / 4$ & $5 / 08$ \\
\hline Large & $2 / 3$ & $2 / 3$ & $1 / 2$ & $5 / 08$ \\
\hline
\end{tabular}

\section{RESULTS AND DISCUSSIONS}

This data envelopment analysis model generates a scalar efficiency ratio and identifies a group of comparative DMUs for each program. Those programs with a positive efficiency ratio of less than 1 are declared as "inefficient" compared to programs with an efficiency ratio of 1. In this study health programs with an efficiency ratio of 1 , while not necessarily efficient in the absolute sense, represent the "best-practice" units when compared with other programs in their subset. Among the 27 programs, 16 had an efficiency ratio of 1 compared to a reference set of DMUs and no slacks; these were then classified as efficient. Eleven were inefficient since their efficiency ratios were less than 1 . DEA identified the relatively more efficient programs and provided the user to differentiate efficient programs with the other programs.

\section{CONCLUSION AND FUTURE ENHANCEMENT}

This paper provides an effective and practical approach for evaluating relative efficiency of Indian rural health care programs especially useful for program management and policy making. It also addresses the correction in the rural health care delivery system to improve the quality of life of our citizens and for the economic and social development of the nation. The future enhancement of this study is to introduce "Business Process Reengineering" technique to redesign the inefficient programs to enhance productivity in Indian rural health care delivery system.

\section{REFERENCES}

[1]NRHM report Government of India, 2005-2015

[2] National Health Policy 2002, Government of India.

[3] A. Charnes, W. W. Cooper, and E. Rhodes, "Evaluating Program and Managerial Efficiency: An Application of Data Envelopment Analysis to Program Follow Through", Management Science, Vol. 27, No. 6, Pp. 668-97, June 1981.

[4]Y. G. Huang, C. P McLaughin, "Relative efficiency in rural primary health care; an application of Data envelopment Analysis." Health Service Res. Vol. 24, No.2, Pp.143-158, June1989.

[5]Majid Zerafat, L. Angiz Adli Mustafa, Ali Emrouznejad, "Ranking efficient decision-making units in data envelopment analysis using fuzzy concept." Vol. 59, Pp .712-719, 2010.

[6]A. Charnes, W.W. Cooper, "Using data envelopment analysis to evaluate the efficiency of economic performance by Chinese cities". Socio-Economic Planning Science, Vol. 23, Pp. 325-344, 1989.

[7] R. D. Banker, R. F. Conrad, and R. P. Strauss, "A Comparative Application of Data Envelopment Analysis and Translog Methods", An Illustrative Study of Hospital Production. Management Science Vol. 32, No. 1, Pp.30-44, January 1986.

[8] R.D. Banker, A. Charnes, W.W. Cooper, "Some model for estimating technical and scale inefficiencies in data envelopment analysis.” Management Science, Vol. 30, No.9, Pp. 1078-1092, 1984.

[9] Nicole Adler, Lea Friedman, Zilla Sinuany-Stern, "Review of ranking methods in the data envelopment analysis context", European Journal of Operational Research.Vol.140, Pp. 249-265, 2002.

[10] A. Charnes, C.T. Clark, W.W. Cooper, B. Golany, "A developmental study of data envelopment analysis in measuring the efficiency of maintenance units in the US air forces", Annals of Operations Research, No. 2, Pp. 95-112, 1985.

[11] W.D. Cook, A. Kress, "A data envelopment model for aggregating preference rankings", Management Science, Vol. 36, No. 11, Pp. 13021310, 1990.

[12] W. D. Cook, D. A. Johnston, "Evaluating suppliers of complex systems: A multiple criteria approach", Journal of the Operational Research Society, Vol. 43, Pp.1055-1061, 1992.

[13] A. Charnes, W.W. Cooper, B. Golany, L. Seiford, J. Stutz, "Foundations of data envelopment analysis for Pareto Koopmans efficient empirical production functions", Journal of Econometrics, Vol. 30, Pp. 91107, 1985.

[14] P. Andersen, N.C. Petersen, "A procedure for ranking efficient units in data envelopment analysis”, Management Science, Vol. 39, Pp. 1261-1264, 1993.

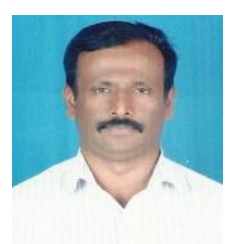

G.M. Satyanarayana is born in Karnataka, India on $13^{\text {th }}$ September 1963. He earned his Undergraduate degree in Industrial\& Production Engineering in 1991 from University of Mysore, Karnataka, Postgraduate degree in Engineering Management from MIT, Manipal from University of Mangalore, Karnataka in the year 1999. Presently he is working as Associate Professor in the Department of Mechanical Engineering, AIT, Karnataka, India. He has published 8 papers in National/ International conferences / journals. He is a Life Member of Indian Society for Technical Education. (E-mail:satyaait@gmail.com)

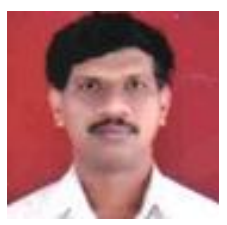

C.T. Jayadeva is born in Karnataka, India on $18^{\text {th }}$ July 1963. He earned his Undergraduate degree in Industrial \& Production Engineering in 1986 from University of Mysore, Karnataka, Postgraduate degree in Industrial Engineering from university of Calicut, Kerala in the year 1993, and Doctoral degree in Quality Management from VTU, India in the year 2008. He worked as Principal at YIT. Hassan, Karnataka and presently working as Professor in the Department of Mechanical Engineering, AIT, Chikmaglur, Karnataka, India. He has published 19 papers in National / International conferences/journals. He is a Life Member of Indian Society for Technical Education. (E-mail: ctjayadeva@yahoo.co.in)

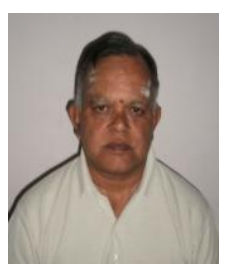

Dr.H.V. Ramakrishna is born in Karnataka, India on $17^{\text {th }}$ April 1957. He earned his Undergraduate degree in Mechanical Engineering in 1980 from University of Mysore, Karnataka, Postgraduate degree in Mechanical Engineering from University of Mysore, Karnataka in the year 1992, and Doctoral degree from Mysore University, Karnataka, India in the year 2005. Presently working as Professor in the Department of Mechanical Engineering, in Malnad College of Engineering, Hassan, Karnataka, India. $\mathrm{He}$ has published 16 papers in National/International conferences/journals. He is a Life Member of Indian Society for Technical Education. (E-mail: hvr_2003@yahoo.com). 